\title{
Atenção Primária à Saúde-Oftalmologia: Percepção Discente Sobre Competências na Formação Médica
}

Primary Health Care-Ophthalmology: Student Perception About Competences in Medical Training

Atención primaria a la salud-oftalmología: percepción discente sobre competencias en la formación médica

Carmem Lúcia Carneiro Leão de Biase ${ }^{1}$

\section{Resumo}

Objetivo: avaliar competências e percepções dos discentes de medicina de uma universidade pública, quanto à sua formação em oftalmologia na atenção primária à saúde. Método: Pesquisa qualitativa que usou estudo de caso, do tipo explicativo, com abordagem hipotético-dedutiva e amostra não probabilística intencional. Os dados foram coletados pelo Objective Structured Clinical Examination (OSCE) e entrevista com perguntas abertas, relacionadas ao tema. Os dados do OSCE foram organizados em planilhas do Excel e tratados com Statistical Package for the Social Sciences e as falas foram exploradas pautando-se na análise temática. Resultados: Os dados apontaram para o fato de que, apesar dos discentes apresentarem formação em oftalmologia para a atenção primária (APS), ela não é advinda exclusivamente da disciplina de oftalmologia, mas também de outros recursos pedagógicos presentes, tanto no currículo formal, quanto no informal. Conclusão: Discentes encontram-se aptos para a assistência em oftalmologia na APS, porém foram identificadas fragilidades em habilidades de

${ }^{1}$ Médica. Coordenadora da Residência Médica em Oftalmologia da Universidade Federal de Alagoas (UFAL). Médica Oftalmologista da UNCISAL. Autora correspondente: Campus A. C. Simões. Av. Lourival Melo Mota, s/n. Tabuleiro dos Martins. 57072-900. Maceió, Al, Brasil. E-mail: carmem.biase@gmail.com 
comunicação e de prescrição medicamentosa.

\section{Descritores: Oftalmologia; Atenção}

\section{Primária à Saúde; Currículo}

\section{Abstract}

Objective: To evaluate the competences and perceptions of medical students of a public university regarding their training in ophthalmology in primary health care. Method: qualitative research that used case study of the explanatory type was used, with a hypothetical-deductive approach and an intentional non-probabilistic sample. Data were collected by the Objective Structured Clinical Examination (OSCE) and interview with open questions related to the subject. The OSCE data were organized in Excel spreadsheets and dealt with the Statistical Package for the Social Sciences and the lines were explored based on thematic analysis. Results: The date pointed to the fact the, although the students present training in ophthalmology in primary care, it is not only the ophthalmology discipline, but also other pedagogical resources present, both in the formal and informal curricula. Conclusion: Students are eligible for ophthalmology care in PHC, weaknesses in communication skills and prescription medication have been identified.

\section{Descriptors: Ophthalmology; Primary Health Care; Curriculum.}

\section{Resumen}

Objetivo: Evaluar habilidades $y$ percepciones de los estudiantes de medicina de medicina de una universidad pública, en cuanto a su formación en oftalmología en la atención primaria a la salud. Método: Se utilizó el estudio de caso del tipo explicativo, con abordaje hipotéticodeductivo y muestra no probabilística intencional. Los datos fueron recogidos por el Objective Structured Clinical Examination (OSCE) y entrevista con preguntas abiertas, relacionadas al tema. Los datos del OSCE se organizaron en las hojas de Excel y se trataron con el Statistical Package for the Social Sciences y las palabras se exploraron pautando en el análisis temático. Resultados: Apuntaron que, a pesar de que los discursos presentaban formación en oftalmología en la atención primaria, no se venía exclusivamente de la disciplina de oftalmología, sino también de otros recursos pedagógicos presentes, tanto 
en el currículo formal, como en el informal. Conclusión: Aunque los estudiantes se encuentren aptos para la asistencia en oftalmología en la APS se identificaron fragilidades en habilidades de comunicación y de prescripción medicamentosa.

\section{Descriptores: Oftalmología; Atención} Primaria a la Salud; Curriculum.

\section{Introdução}

O ensino médico brasileiro está em debate, quanto aos métodos e seus conteúdos, vivenciando um processo de transformação desde 2001, com a promulgação das Diretrizes Curriculares Nacionais (DCN). Desde então, diversas tentativas de mudanças foram realizadas visando à eficácia na formação e capacitar o médico recém-graduado para lidar com a realidade do contexto social do país ${ }^{(1)}$. Essas diretrizes instituíram linhas gerais para a formação médica, referendando que o graduando deve ter formação generalista, humanista, crítica e reflexiva, pautada na ética e no processo saúde-doença nos diferentes níveis de atenção, com ações de promoção, prevenção, recuperação e reabilitação, com foco na integralidade da assistência, responsabilidade social e compromisso com a cidadania ${ }^{(2-3)}$.

A partir das DCN de 2001 e 2014, um dos principais desafios das escolas médicas foi a implementação de uma matriz curricular com integração entre os componentes curriculares, além de não sobrepor conteúdo, dos distintos componentes e especialidades. As DCN, também, estabeleceram competências gerais, comuns para os cursos de Medicina, Enfermagem e Nutrição, que devem ser adquiridas na graduação, tais como: atenção à saúde, tomada de decisão, administração, gerenciamento, comunicação e educação permanente. Portanto, as mudanças curriculares na graduação em saúde, especialmente, em medicina, devem ajustar-se às $\operatorname{diretrizes}^{(4)}$.

As DCN de 2014 apresentam um avanço em relação às de 2001, no que dizem respeito à exigência de pelo menos $30 \%$ da carga horária do estágio obrigatório, em regime de internato, implementado no Sistema Único de Saúde (SUS), na atenção básica e em serviço de urgência e emergência, visando o acesso a direitos sociais, equidade, qualificação dos serviços públicos, mudanças nas políticas de assistência à saúde, inclusão social e democratização do ensino superior ${ }^{(5-6)}$. 
O planejamento dos programas das disciplinas, pautado nas competências e habilidades segundo as DCN, leva à obtenção da excelência nas escolas médicas, cujo objetivo é assegurar a qualidade dos serviços de saúde prestados pelos egressos, refletindo em respeito e bem-estar para com os pacientes. Nos primeiros semestres do curso, competências e habilidades apresentam-se em menor concentração, sendo exploradas progressivamente, até $\mathrm{o}$ final $\mathrm{da}$ graduação $^{(6)}$.

Competência consiste na capacidade de mobilizar e integrar o conjunto de conhecimentos especializados e saberes, recursos e habilidades para a resolução de problemas num contexto profissional determinado. Habilidade, para este autor, consiste na mobilização de conhecimentos e capacidades para resolver uma situação-problema da vida real, sem ao menos pensar ou planejar $^{(7)}$.

Os cursos de graduação em medicina encontram-se com seu Projeto Pedagógico do Curso (PPC), ainda organizado no modelo flexneriano. Tal modelo elege o ensino hospitalocêntrico e promove a separação entre ciclo básico e profissional. Embora, as reformas tenham surgido para modernizar o ensino, visando uma base científica, também trouxe para esta formação, características mecanicistas e biologicistas, estimulando a especialização profissional ${ }^{(8-9)}$.

A Atenção Primária em Saúde (APS) é a via de ingresso no sistema público de saúde, que se encontra no âmbito da gestão municipal, sendo fundamental para a estruturação do SUS ${ }^{11}$. Outra publicação relata que a APS é ponto de convergência entre políticas de saúde e ensino médico, na medida em que a Constituição Federal aponta para a integração sistema de saúde e necessidades de saúde da população. Além disso, é a Estratégia de Saúde da Família (ESF), o modelo prioritário para a (re)organização da APS e a atenção à saúde no país. Entretanto, a desigualdade de acesso e o atendimento de qualidade na APS têm criado inúmeras dificuldades para o desenvolvimento dos demais níveis da $\operatorname{APS}^{(10)}$.

As demandas de saúde no Brasil, decorrentes da transição epidemiológica e demográfica contribuíram para implementação da Resolução 3/2014, que institui as $\mathrm{DCN}$, na perspectiva de corroborar a necessidade de um egresso com perfil generalista e familiarizado com a APS, uma vez que $80 \%$ das queixas na área de saúde podem e 
devem ser resolvidas na $\operatorname{APS}^{(11)}$. O ensino de graduação em medicina visa habilitar o egresso generalista a diagnosticar e tratar doenças, dentre elas, as oculares, estando apto a fazer o pronto atendimento $\mathrm{e} \quad \mathrm{o}$ encaminhamento adequados, na APS. A abordagem precoce dos problemas oculares deve ser feita na APS, evitando, assim, complicações oculares $^{(12)}$.

Os modelos tradicionais de ensino não atendem à formação generalista, conforme preconizam as DCN, uma vez que levam o aluno a uma postura passiva. A metodologia que mais se adequa à integração teoria/prática, ensino/serviço é a ativa, por estimular a formação de competências e habilidades, tornando o discente construtor do seu próprio conhecimento $^{13}$. Nessa perspectiva, o curso de Medicina da Faculdade de Medicina da Universidade Federal de Alagoas (FAMED/UFAL) vem trabalhando com metodologias ativas, numa proposta generalista, com ênfase na $\operatorname{APS}^{(13)}$.

$\mathrm{O}$ fato de exercer a medicina na área de oftalmologia, em um hospital universitário há 13 anos, desenvolvendo preceptoria, junto aos discentes e residentes, trouxe inquietações à respeito da formação médica, no que concerne à APS. A relevância do presente estudo alicerça-se na urgência de avaliar como as mudanças da matriz curricular do curso de medicina da FAMED, realizadas em 2001 e 2014 estão repercutindo na formação, no tocante à oftalmologia na APS. O estudo objetivou avaliar as competências e a percepção dos discentes da FAMED, sobre sua formação em oftalmologia, no âmbito da APS.

\section{Método}

Estudo de caso do tipo explicativo, com abordagem hipotéticodedutiva e amostra não probabilística intencional. Pesquisa descreve que o estudo de caso é o método mais adequado para conhecer em profundidade todas as nuances de um determinado fenômeno. Para amostra não probabilística intencional são escolhidas pessoas que provavelmente detêm o conhecimento do tema a ser estudado, contribuindo para obtenção fidedigna dos dados ${ }^{(14)}$.

Foram critérios de inclusão: ser discente do internato da graduação em Medicina da FAMED, o que corresponde ao $11^{\circ}$ e $12^{\circ}$ período do curso e matriculados, no primeiro semestre de 2016. O estudo foi 
aprovado pelo Comitê de Ética em Pesquisa, sob $\mathrm{n}^{\circ} 1.500 .710$ e os participantes, após aceitação do convite e orientação do TCLE, o $\operatorname{assinaram}^{(15-}$ 16)

Os dados foram obtidos tendo como instrumento de coleta de dados o Objective Structured Clinical Examination (OSCE) e entrevista com perguntas abertas, relacionadas ao tema. Esses dados foram organizados $\mathrm{e}$ tabulados em planilhas do Excel e tratados com StatisticalPackage for the Social Sciences ${ }^{(17-18)}$, (SPSS versão 22.0). O OSCE é mundialmente aceito, válido, fidedigno e eficaz, no qual a simulação do exame clínico é feita, para observar comportamento e habilidades, em determinada situação. A avaliação das habilidades médicas pelo OSCE é muito utilizada em países da Europa e nos Estados Unidos. Essa técnica, também é usada em outros cursos da área da saúde $\mathrm{e}^{(17)}$.

Para a realização do OSCE, foram criadas quatro estações, nas salas de aula da FAMED. Cada estação abordou diferentes temas relacionados ao atendimento em oftalmologia na APS: Estação 1 - Tema: Avaliação da acuidade visual - Queixa: Baixa visual em um olho - medida da acuidade visual; Estação 2 - Tema: Doenças sistêmicas presentes no âmbito da APS e que podem gerar comprometimento ocular quando não controladas - coleta da história da doença atual (HDA), antecedentes pessoais (AP) e formulação de no mínimo três hipóteses diagnósticas; Estação 3 - Tema: Paralisia facial periférica (PFP) lagoftalmo - diagnóstico e tratamento inicial - prescrição correta de medicação tópica (colírio) - necessidade de proteção corneana; Estação 4 - Tema: Olho vermelho/conjuntivite diagnóstico, prescrição correta da medicação tópica (colírio) e confecção de atestado/licença médica.

Em cada estação, havia um paciente simulado - ator/atriz - e uma equipe de filmagem disposta discretamente para não interferir no atendimento. Os discentes permaneceram em uma sala de espera, liberados um a um, sem que houvesse contato de um discente com outro, no decorrer das estações. A elaboração das estações foi baseada na literatura de oftalmologia $^{(19-20)}$.

As habilidades foram classificadas como: presente, quando foi desenvolvida em sua plenitude; incompleta, quando realizada parcialmente; e ausente, quando não realizada. Para a operacionalização estatística dos dados quantitativos foi considerado: o valor numérico um (1) 
para habilidade presente; dois (2)

habilidade incompleta e três (3) habilidade ausente. Cada estação teve duração de cinco minutos e um sinal de comando era dado tanto para o início quanto para o término. As atividades desenvolvidas pelos discentes, nas estações clínicas simuladas foram gravadas em vídeos pelas equipes de filmagem, com permissão prévia dos discentes.

Para aprofundamento dos dados optou-se por um segundo instrumento de coleta, que foi um questionário com duas perguntas abertas: 1) Você se sente apto para atender pacientes com queixas oftalmológicas no âmbito da atenção APS? 2) Como você percebe o curso de graduação em medicina da UFAL, especificamente, a disciplina oftalmologia, em relação a formação do profissional, no tocante à assistência em saúde ocular na APS? Transcritas as respostas analisaram-se as falas pautando-se na análise temática. As falas dos discentes que participaram da pesquisa foram identificadas pela letra "D”, seguida de um número correspondente à ordem cronológica da leitura das respostas, que foi realizada pela pesquisadora.

Uma leitura flutuante e a identificação do material de análise foi feita, com foco no objeto de estudo. As falas semelhantes foram codificadas em blocos e identificadas as unidades de contexto com suas respectivas unidades de registro, guiadas pelo surgimento das categorias $^{(21)}$.

\section{Resultados e Discussão}

As tabelas a seguir demonstram os resultados das estações do OSCE. Na Tabela 1 estão apresentados os dados referentes à estação cujo tema foi Avaliação da acuidade visual - Queixa: Baixa visual em um olho - medida da acuidade visual.

$\mathrm{Na}$ Tabela 1, estação 1, habilidade 1, que se refere à comunicação inicial entre discente e paciente simulado identificou-se que $41,2 \%$ deles cumprimentaram $\mathrm{o}$ paciente $\mathrm{e}$ apresentaram-se ao mesmo, configurando a habilidade presente. Nas estações subsequentes, os percentuais dessa mesma habilidade foram de $11,8 \% ; \quad 29,4 \% \quad$ e $\quad 23,5 \%$, respectivamente.

A habilidade 1 esteve incompleta em $41,2 \% ; 76,5 \% ; 47,1 \%$ e $64,7 \%$ em todas as estações, pois os discentes cumprimentaram o paciente, porém não se apresentaram e ainda $17,6 \%, 11,8 \%$, $23,5 \%$ e $11,8 \%$ dos discentes, ao entrarem na estação 1, não cumprimentaram e nem se apresentaram 
sem chance de estabelecer a empatia

Tabela 1: Avaliação da Acuidade Visual

\begin{tabular}{lcc}
\hline Habilidade & $\boldsymbol{n}$ & $\%$ \\
\hline Habilidade 1: Cumprimentou o paciente e apresentou-se & 7 & 41,2 \\
1. Presente & 7 & 41,2 \\
2. Incompleta & 3 & 17,6 \\
3. Ausente & 15 & 88,2 \\
Habilidade 2: Fez anamnese & 1 & 5,9 \\
1. Presente & 1 & 5,9 \\
2. Incompleta & 14 \\
3. Ausente & 14 \\
Habilidade 3: Aferiu a acuidade Visual & 82,4 \\
1. Presente & 3 \\
2. Incompleta & 0 \\
3. Ausente & 17,6 \\
Habilidade 4: Formulou a hipótese diagnóstica & 0,0 \\
1. Presente & 15 \\
2. Incompleta & 2 \\
3. Ausente & 0 \\
\hline
\end{tabular}

Nesse contexto, observou-se que os resultados encontrados, contrariam outro estudo que explicita a questão da empatia entre médico e paciente, a qual é importante, porque deixa o último mais seguro e disposto a informar com desenvoltura seus problemas, sintomas e dúvidas ${ }^{(22-23)}$.

Estudos relatam a necessidade de se introduzir na graduação, disciplina que trate da comunicação para auxiliar o futuro médico no trato com o paciente e aponta, que essa mudança envolve a ruptura com o atual modelo de atenção. Assim, a formação acadêmica deve preparar médicos para lidar de forma humanizada, somada às inovações tecnológicas e postura ética, como base do atendimento ${ }^{24}$. $\mathrm{Na}$ academia, várias teses abordam a relação médicopaciente, sob diferentes perspectivas. Entretanto, essa relação, ainda constitui um tema marginal, frente à hegemonia do modelo biologicistas, que domina a formação médica na sociedade ${ }^{(23-25)}$.

Quanto às habilidades 2, 3 e 4, que correspondem, respectivamente, à realização da anamnese, aferição da acuidade visual e formulação da hipótese diagnóstica, os discentes 


\section{Biase CLCL 758 \\ Atenção Primária à Saúde-Oftalmologia}

atingiram aproveitamento acima de $80 \%$. Sendo $88,2 \%$ na realização da anamnese; $82,4 \%$ na aferição da acuidade visual e $88,2 \%$ na formulação da hipótese diagnóstica, presentes na estação 1. Comparando-se os dados do OSCE com os da análise temática, percebeu-se que há momentos na formação médica, que os discentes apreendem conhecimentos e vivenciam experiências em oftalmologia, mas que esses conhecimentos não são exclusivamente advindos da disciplina, como se visualiza nas falas:

"As aulas teóricas são extremamente objetivas sobre os assuntos mais corriqueiros da prática médica oftalmológica e não tivemos praticamente nenhuma aula prática durante o período que passamos pela matéria" (D1).

"[...] praticamente não tivemos aula prática [...]" (D1).

"A oftalmologia do curso da UFAL, deixa a desejar no aspecto da preparação do aluno para a identificação e condução das patologias oculares" (D5).

"Não sinto segurança na própria realização do exame básico para definir algumas doenças. Traz certa insegurança ao receber um paciente com queixas oftalmológicas" (D5).

"Não vemos muito sobre as doenças oftalmológicas durante nossa formação" (D10).

O conhecimento dos discentes, expresso pelas suas concepções curriculares e métodos organizacionais, resulta de visões específicas da realidade, que incidem sobre conhecimento, valores e motivações dos alunos. Esses resultados corroboram com estudo realizado com estudantes de Medicina da Faculdade de Marília/SP que aponta atividades extracurriculares como recurso de aprendizagem que assumem tanto o lugar de produto no currículo oculto, quanto sua produção $^{(26)}$.

$\mathrm{Na}$ Tabela 2, habilidade 2, referente à elaboração da história da doença atual (HDA) e antecedentes pessoais (AP) foi observado que $82,4 \%$ dos discentes as realizaram de forma satisfatória, mostrando bom desempenho quanto à semiologia na $\mathrm{AP}$, questionando ao paciente/ator a respeito de doenças sistêmicas como o DM e HAS que, quando não prevenidas ou tratadas podem comprometer a saúde ocular. Os dados encontrados na presente pesquisa vão ao encontro de estudo que identificou o envolvimento de estudantes de medicina com atividades extracurriculares, como uma necessidade por parte desses alunos, para aquisição de conhecimentos e novas experiências que complementem o currículo formal ${ }^{(25)}$.

$\mathrm{Na}$ estação 2, habilidade 3 analisou-se a capacidade do discente em formular ao menos três hipóteses diagnósticas relacionadas ao paciente 
em tela. Salienta-se que o paciente - ator foi treinado previamente para informar aos discentes, quando questionado no momento da coleta da HDA e AP, que sofria de DM e HAS há muitos anos, e que essas doenças não tinham um seguimento médico e nem controle adequados até então.

Os resultados demonstraram uma variada gama de hipóteses diagnósticas aventadas pelos discentes. Nessa perspectiva, constatou-se que os dados apresentados na Tabela 2, habilidade 3 corroboram com as DCN que citam no art $3^{\circ}$, que o discente de medicina deve ter formação geral, humanista crítica, reflexiva e ética. Além de capacidade para atuar nos níveis de atenção à saúde, com ações de promoção, prevenção, recuperação e reabilitação da saúde, nos âmbitos individual e coletivo ${ }^{(20)}$.

Tabela 2: Doenças Sistêmicas Presentes no Âmbito da APS e Que Podem Gerar Comprometimento Ocular Quando Não Controladas

\begin{tabular}{lcc}
\hline Habilidade & $\mathbf{n}$ & $\mathbf{\%}$ \\
\hline Habilidade 1: Cumprimentou o paciente e apresentou-se & 2 & 11,8 \\
1. Presente & 13 & 76,5 \\
2. Incompleta & 2 & 11,8 \\
3. Ausente & 14 & 82,4 \\
Habilidade 2: Colheu HDA e AP & 2 & 11,8 \\
1. Presente & 1 & 5,9 \\
2. Incompleta & & 52,9 \\
3. Ausente & 9 & 35,3 \\
Habilidade3: Formulou hipóteses diagnósticas com acertos & 6 \\
1. Presente & 2 & 11,8 \\
2. Incompleta & 2 \\
3. Ausente & 2 & 5 \\
\hline
\end{tabular}

$\mathrm{Na}$ estação 2 solicitou-se a formulação de três hipóteses diagnósticas para que a tarefa fosse considerada presente, sendo que 52,9\% dos discentes foram capazes de formulá-las e 35,3\% não conseguiram de maneira completa. Considerou-se a habilidade incompleta quando o estudante citava apenas uma hipótese.
Os discentes que não formularam sequer uma hipótese diagnóstica $(11,8 \%)$ se enquadraram na habilidade ausente. Nesse sentido, pesquisa aponta que o raciocínio e habilidade clínica do futuro médico sejam desenvolvidos na APS e que esta prática esteja presente longitudinalmente ao longo do curso ${ }^{(25)}$. 
Dentre os objetivos da ementa da disciplina de oftalmologia da FAMED identificou-se a necessidade de oferecer conhecimentos sobre a especialidade para todo médico generalista, e salientar as características de afecções que devem ser encaminhadas ao oftalmologista ${ }^{31}$. O que se observou na seguinte fala:

\section{"Na minha época, vimos assuntos que possivelmente aparecem na atenção básica" (D4).}

Porém, observa-se nas falas dos discentes a crítica em relação à escassez de aulas práticas nesta disciplina:

"[...] não tivemos praticamente nenhuma aula prática durante o período que passamos pela matéria" (D1).

"[...] Um dos grandes problemas na minha formação foi a escassez de práticas, seja em ambulatório ou em outros locais de desenvolvimento desse tipo de atividade durante a graduação" (D3).

Os relatos apresentados são referendados em estudo que descreve a APS, como cenário a ser utilizado como campo de aulas práticas, com vistas a consolidar não somente a formação dos profissionais da área médica, mas sobretudo por ser ponto de convergência entre as DCN e os projetos político-pedagógicos contemporâneos, consonantes com o SUS $^{(1)}$. Na Tabela 3, habilidade 2, analisou-se a formulação da hipótese diagnóstica.

Foi observado que $82,4 \%$ dos discentes formularam a hipótese diagnóstica com acerto afirmando tratar-se de uma paralisia facial periférica, que $5,9 \%$ o fizeram de maneira incompleta e que $11,8 \%$ não formularam a hipótese, ou a fizeram erroneamente.

Tomando-se como referência as discussões da literatura e a conjuntura sociocultural e econômica, infere-se que as intenções da educação superior consistem num conjunto propositado e subjetivo com formação profissional mais ampla. Desde a década de 1980, intensificou-se o número de trabalhos que têm evidenciado o impacto do contexto universitário, constituído tanto pelas atividades do currículo formal (obrigatórias), quanto pelas extracurriculares (não obrigatórias), sobre o desenvolvimento psicossocial e cognitivo do estudante na universidade ${ }^{(26)}$.

$\mathrm{Na}$ habilidade 3 , que se refere à necessidade do discente orientar $\mathrm{o}$ tratamento oclusivo noturno do olho acometido pela paralisia facial, observando-se que a habilidade foi ausente em 76,5\%. Demonstrou-se então, uma lacuna na prevenção da saúde ocular na APS, dada a 
importância de tal orientação. Os cuidados oculares em pacientes com paralisia facial periférica representam a parte menos controversa do tratamento. Os olhos precisam ser lubrificados durante o dia com colírios do tipo lágrima artificial para a proteção da córnea contra abrasões e durante a noite recomenda-se o uso de pomadas e tampões oclusivos, além da colocação de umidificadores nos quartos ${ }^{(27)}$.

\section{Tabela 3: Paralisia Facial Periférica - Lagoftalmo}

\begin{tabular}{lcc}
\hline Habilidade & $\boldsymbol{n}$ & $\%$ \\
\hline Habilidade 1: Cumprimentou o paciente e apresentou-se & 5 & 29,4 \\
1. Presente & 8 & 47,1 \\
2. Incompleta & 4 & 23,5 \\
3. Ausente & 14 & 82,4 \\
Habilidade 2: Formulou hipótese diagnóstica & 1 & 5,9 \\
1. Presente & 2 & 11,8 \\
2. Incompleta & & \\
3. Ausente & 4 & 23,5 \\
Habilidade 3: Orientou o paciente sobre a necessidade de se ocluir o olho & 76,5 \\
acometido à noite & 13 \\
1. Presente & & \\
2. Ausente & 1 & 5,9 \\
Habilidade 4: Prescreveu colírio lubrificante & 8 \\
1. Presente & 8 & 47,1 \\
2. Incompleta & 47,1 \\
3. Ausente & & \\
\hline
\end{tabular}

Pela ausência de celeridade para consulta com o especialista em oftalmologia, essas medidas iniciais devem ser orientadas pelo médico generalista, no âmbito da APS. Vale ainda salientar, que nessa habilidade, os resultados se dividiram em ausente e presente. Não houve resultado no qual a habilidade foi avaliada como incompleta. Apenas 23,5\% dos discentes orientaram a paciente/atriz quanto à necessidade de se ocluir o olho acometido à noite.
$\mathrm{Na}$ Tabela 3, habilidade 4, um discente soube prescrever o colírio lubrificante protetor da córnea, correspondendo a 5,9\% dos discentes com habilidade presente. Dos discentes que participaram desta pesquisa $47,1 \%$ foram considerados com habilidade incompleta, ao orientarem a paciente/atriz da necessidade de uso do colírio lubrificante, porém, não souberam prescrevê-lo efetivamente. Outros $47,1 \%$ sequer citaram a necessidade de uso do referido colírio, o 
que é comprometedor, pois é importante empregar medidas preventivas da exposição corneana para prevenir a cegueira irreversível ${ }^{(28-29)}$. As falas a seguir demonstram a necessidade de conhecimento oftalmológico voltado para a prática na APS:

\begin{abstract}
"Sem conseguir clareza na formulação concreta do diagnóstico, tendo em mente a importância da saúde ocular na qualidade de vida do individuo, acabo optando pelo encaminhamento ao especialista" (D4).

"Em queixas mais complexas, geralmente me faltam opções de diagnóstico ou tratamento, por falta de conhecimento, e dessa forma, certamente encaminho mais que o necessário [...]" (D10).
\end{abstract}

Essa pesquisa identificou que há um despreparo por parte dos discentes no que se refere à prescrição de colírios em oftalmologia. Fato esse, que foi confirmado na quarta estação, na qual um quadro clínico de conjuntivite bacteriana foi descrito e o discente, como tarefa, deveria prescrever antibióticos tópicos.

$\mathrm{Na}$ Tabela 4, habilidade 2 foi observado que $88,2 \%$ dos discentes formularam a hipótese diagnóstica corretamente, tornando-a presente $\mathrm{e}$ $11,8 \%$ não o fizeram, configurando-a ausente.

Neste item, não foram encontradas respostas incompletas, já que se considerou como acerto o diagnóstico de conjuntivite bacteriana, quadro frequente na APS. E 11,8\% formularam a hipótese diagnóstica da maneira incorreta, identificando-a de conjuntivite viral.

Vale salientar que a paciente/atriz exibia, a imagem de um olho com sinais de conjuntivite com abundante secreção purulenta, quadro típico de uma conjuntivite bacteriana. $\mathrm{Na}$ conjuntivite viral, a secreção não se faz presente, sendo causada, principalmente, pelo adenovírus e desenvolve-se com lacrimejamento, vermelhidão, desconforto e fotofobia. Já a bacteriana, geralmente, é causada por uma das bactérias (Staphylococcus aureus, Streptococcus pneumoniae, Haemophylus influenza e Moraxella catarrhalis) manifestando-se com lacrimejamento, hiperemia e edema ocular, prurido e secreção purulenta ${ }^{(30)}$.

Ressalta-se a importância do diagnóstico diferencial entre conjuntivite viral e bacteriana. Na viral, o tratamento consiste apenas, em higiene com soro fisiológico gelado e na bacteriana, a antibioticoterapia tópica se faz necessário, tão logo o diagnóstico tenha sido firmado. Em relação à habilidade 3 , referente à higiene ocular com soro fisiológico, observou-se que $94,1 \%$ dos discentes a mantiveram e 
$5,9 \%$ não teceram comentários a respeito.

Para a habilidade 4 , relativa à prescrição do colírio antibiótico, apenas $29,4 \%$ dos discentes se encontraram aptos a prescrever o colírio, citando o antibiótico e a posologia adequada a ser seguida pela paciente/atriz. A habilidade foi considerada incompleta em $64,7 \%$ dos discentes, quando estes só citaram a necessidade do uso do colírio antibiótico, sem prescrevê-lo com posologia adequada. E 5,9\% deles não atentaram para a necessidade de prescrever colírio antibiótico, de forma que essa habilidade foi considerada ausente.

\section{Tabela 4: Olho Vermelho/Conjuntivite}

\begin{tabular}{|c|c|c|}
\hline Habilidade & $\mathbf{n}$ & $\%$ \\
\hline \multicolumn{3}{|c|}{ Habilidade 1: Cumprimentou o paciente e apresentou-se } \\
\hline 1. Presente & 4 & 23,5 \\
\hline 2. Incompleta & 11 & 64,7 \\
\hline 3. Ausente & 2 & 11,8 \\
\hline \multicolumn{3}{|c|}{ Habilidade 2: Formulou hipótese diagnóstica } \\
\hline 1. Presente & 15 & 88,2 \\
\hline 2. Ausente & 2 & 11,8 \\
\hline \multicolumn{3}{|c|}{ Habilidade 3: Manteve higiene ocular com soro fisiológico } \\
\hline 1. Presente & 16 & 94,1 \\
\hline 2. Ausente & 1 & 5,9 \\
\hline \multicolumn{3}{|c|}{ Habilidade 4: Prescreveu colírio antibiótico } \\
\hline 1. Presente & 5 & 29,4 \\
\hline 2. Incompleta & 11 & 64,7 \\
\hline 3. Ausente & 1 & 5,9 \\
\hline \multicolumn{3}{|c|}{ Habilidade 5: Forneceu atestado médico } \\
\hline 1. Presente & 11 & 64,7 \\
\hline 2. Incompleta & 6 & 35,3 \\
\hline 3. Ausente & 0 & 0,0 \\
\hline
\end{tabular}

Embora desde 2008 conste na ementa da disciplina de oftalmologia ${ }^{(30)}$ preocupação em "oferecer conhecimentos sobre a especialidade que deve ter todo médico generalista" observou-se uma carência por parte dos discentes em conduzir as queixas oftalmológicas de maneira satisfatória na APS. Destaca-se que, a habilidade de comunicação, refere-se à necessidade do discente cumprimentar e se apresentar ao paciente antes de se ater a qualquer outro fato, seja ele médico ou não. A carência desta habilidade foi observada 
no desenrolar do OSCE e nas respostas às perguntas abertas aos discentes.

Quanto à última habilidade da Tabela 4, contato com outras pessoas nas primeiras 48 horas de evolução do quadro, este deve ser evitado pela possibilidade de contágio, sendo necessário o afastamento legal das atividades profissionais e/ou escolares. Nessa habilidade identificou-se que $64,7 \%$ o prescreveram de maneira adequada (3 a 7 dias). No entanto, a habilidade incompleta ocorreu em $35,3 \%$ dos discentes, ao emitirem atestado inferior a dois dias, tempo insuficiente para que a volta do paciente ao trabalho ou escola ocorra de maneira segura. O tempo de evolução da conjuntivite bacteriana é de 3 a 5 dias e neste período o afastamento legal das atividades faz-se necessário $^{(28,30)}$.

\section{Conclusão}

Diante dos resultados do OSCE conclui-se que os discentes de medicina da FAMED/UFAL encontram-se aptos para a assistência em oftalmologia na APS, entretanto, identificaram-se fragilidades em habilidades de comunicação e de prescrição medicamentosa; As falas dos sujeitos, para as perguntas abertas corroboraram com a proposta de introdução de aula prática com temas voltados à APS, na disciplina de oftalmologia; $\mathrm{O}$ conhecimento evidenciado no OSCE foi oriundo, tanto do currículo formal quanto do oculto; Há vivências práticas desses discentes, no transcorrer da formação acadêmica, em outras disciplinas, favorecendo o aprendizado para a APS;

O estudo possibilitou a reflexão sobre a formação em oftalmologia, no âmbito da APS, direcionando pontos de fragilidades, permitindo que se apontem sugestões pertinentes ao aprendizado. Favoreceu uma mudança na construção do conhecimento tanto para a preceptora do ambulatório de oftalmologia do HUPPA/UFAL, quanto para os discentes que frequentam a disciplina de oftalmologia. Esta pesquisa demonstrou a importância do processo ensino aprendizagem na formação discente em caráter geral, humanista, crítico, reflexivo, ético, condizente com o PPP do curso de medicina da FAMED e suas diretrizes.

\section{Referências}

1. Franco CAGS, Cubas MR, Franco RS. Currículo de Medicina e as Competências Propostas pelas Diretrizes Curriculares. Rev bras educ med. 2014; 38(2):221-30. 
2. Gomes AP, Costa JRB, Junqueira TS, Arcuri MB, Siqueira-Batista R. Atenção Primária à Saúde e Formação Médica: entre episteme e práxis. Rev bras educ med. 2012; 36(4):541-09.

3. Rios IC, Sirino CBA. Humanização no Ensino de Graduação em Medicina: o olhar dos estudantes. Rev bras educ med. 2015; 39(3):401-09.

4. Brasil. Ministério da Educação. Conselho Nacional de Educação. Diretrizes Curriculares Nacionais do Curso de Graduação de Medicina. Câmara de Educação Superior. Resolução CNE/CES 4/2001. Diário Oficial [da] República Federativa do Brasil, Poder Executivo, Brasília, 2001. Disponível em: http://portal.mec. gov.br/cne/arquivos/pdf/CES04.pdf.

5. Nogueira MI. As Mudanças na Educação Médica Brasileira em Perspectiva: Reflexões sobre a Emergência de um Novo Estilo de Pensamento. Rev bras educ med. 2009; 33(2):262-70.

6. Brasil. Ministério da Educação. Conselho Nacional de Educação. Diretrizes Curriculares Nacionais do Curso de Graduação de Medicina. Resolução CNE/CES 3/2014. Diário Oficial [da] República Federativa do Brasil, Poder Executivo, Brasília, 2014. Disponível em:http://portal.mec. gov.br/index.php?option=com_docman $\&$ view $=$ download\&alias $=15514$-pces 1 16-14\&Itemid=30192.

7. Perrenoud P. Avaliação da excelência à regulação das aprendizagens, entre duas lógicas. Porto Alegre: Artmed; 1999.
8. Boelen C, Pearson D, Kaufman A, Rourke J, Woollard R, Marsh DC, et al. Producing a socially accountable medical school. Med Teach. 2016; 38(11):1078-91.

9. Gomes AP, Rego, S. Transformação da educação médica: é possível formar um novo médico a partir de mudanças no método de ensino-aprendizagem? Rev bras educ med 2011; 35(4):55766.

10. Mendes EV. A construção social da atenção primária à saúde. Brasília: CONASS; 2015.

11. Silva MCLSR, Silva L, Bousso RS. A abordagem à família na Estratégia Saúde da Família: uma revisão integrativa da literatura. REUSP. 2011; 45(5):1250-55.

12. Castagno VD, Fassa AG, Silva MC, Carret MLV. Carência de atenção à saúde ocular no setor público: um estudo de base populacional. Cad. Saúde Públ. 2009; 25(10): 2260-72.

13. Universidade Federal de Alagoas. Faculdade de Medicina/FAMED. Projeto Político Pedagógico do Curso de Medicina. Maceió-AL; 2013.

14. Wesley RSF, Charbel JCJ. Utilizando estudo de caso(s) como estratégia de pesquisa qualitativa: boas práticas e sugestões. Estudo \& debate. 2011; 18(2):7-22.

15. Fontanella BJB, Ricas J, Turato ER. Amostragem por saturação em pesquisas qualitativas em saúde: contribuições teóricas. Cad. Saúde Públ. 2008; 24(1):17-7. 
16. Freitas CM, Freitas CASL, Parente JRF, Vasconcelos MIO, Lima GK, Mesquita KO et al. Uso de metodologias ativas de aprendizagem para a educação na saúde: análise da produção científica. Trab. Educ. Saúde. 2015; 13(supl. 2):117-30.

17. Mitchell ML, Henderson A, Groves M, Dalton M, Nulty D. The objective structured clinical examination (OSCE): Optimising its value in the undergraduate nursing curriculum. Nurse Educ Today. 2009; 29(4):398-04.

18. SPSS. Statistical Package for Social Sciences, versão 22.0 para o sistema operacional Windows (SPSS Inc., Chicago, IL); 2016.

19. Guzzo G, Lopes, JMC. Tratado de medicina de família e comunidade: princípios, formação e prática. Porto Alegre: Artmed; 2012.

20. Duncan BB, Schimidt MI, Giugliani ERJ. Medicina ambulatorial: condutas de atenção primária baseadas em evidências. Porto Alegre: Artmed; 2013.

21. Minayo MCS. O desafio do conhecimento: pesquisa qualitativa em saúde. São Paulo: Hucitec; 2011.

22. Terra SRAM, Guaraldo MCMS. O humano e as relações humanas nas ações da saúde. Serviço Social \& Saúde. 2011; 4(4):10-1.

23. Cacioppo JT, Berntson G. Empathy: from bench to bedside. London: Decety; 2011.

24. Miyamoto ACC, Struckel AC. Percepção dos pacientes sobre uma clínica oftalmológica de Maringá. Cad. Administração. 2012; 20(1):30-42.
25. AS, Peres CM, Andrade Garcia SB. Atividades extracurriculares: multiplicidade e diferenciação necessárias ao currículo. Rev. Bras. Educ. 2007; 31(3): 203-11.

26. Demarzo MMP. Diretrizes para o ensino na atenção primária à saúde na graduação em medicina. Rev bras educ med. 2012; 36(1):143-48.

27. Universidade Federal de Alagoas. Faculdade de Medicina/FAMED. Ementa da disciplina de oftalmologia do Curso de Medicina. Maceió-AL; 2008.

28. Axelsson S, Berg T, Jonsson L, Engstrom M, Kanerva M, Pikaranta A, et al. Rednisolone in Bell's palsy related to treatment start and age. Otol neurotol. 2011; 32(1):141-46.

29. Rahman I, Sadiq SA. Ophthalmic management of facial nervepalsy: a review. Surv ophthalmol. 2007; 52(2):121-44.

30. Soares AS, Adam Netto A, Soares AS. Análise da prevalência de conjuntivite no atendimento emergencial do serviço de oftalmologia do Hospital Universitário da Universidade Federal de Santa Catarina nos anos de 2004 a 2008. Arq. Catarinenses Med. 2010; 39(2):50-5. 